RICYDE. Revista Internacional de Ciencias del Deporte doi: $10.5232 /$ ricyde

Rev. int. cienc. deporte

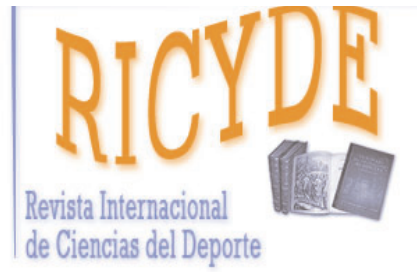

RICYDE. Revista Internacional de Ciencias del Deporte VOLUME XI - YEAR XI

Pages:387-399 ISSN:1885-3137

Issue 42 - October - 2015

\title{
The effects of various visual conditions on the gait cycle in children with different level of motor coordination - a pilot study Cómo afectan diferentes condiciones visuales a la marcha en niños con diferente nivel de coordinación motriz - un estudio piloto
}

\author{
Miriam Palomo-Nieto, Rudolf Psotta, Adrian Agricola, \\ Reza Abdollahipour, Ludvik Valtr \\ Faculty of Physical Culture Palacky University, Olomouc. Czech Republic
}

\begin{abstract}
The importance of vision and the visual control of movement have been addressed in the literature related to motor control. Many studies have demonstrated that children with low motor competence in comparison to their typically developing peers may rely more heavily on vision to perform movements. The aim of the study was to highlight the effects of different visual conditions on motor performance during walking in children with different levels of motor coordination. Participants ( $n=8$, Mean age $=8.5 \pm .5$ years) were divided into typical development (TD) and low motor coordination (LMC) group. They were asked to walk along a 10-meter walkway provided by Optojump-Next instrument that was placed in a portable construction $(15 \times 3 \times$ $2.5 \mathrm{~m})$. This construction was surrounded by dark blue fibers in which all participants perceived the same visual information. They walked in a self-selected speed under four visual conditions: full vision (FV), limited vision $150 \mathrm{~ms}$ (LV-150), limited vision $100 \mathrm{~ms}$ (LV-100) and non-vision (NV). For visual occlusion during walking in LV-150 and LV-100, participants were equipped with Plato Goggles that opened for 150 and $100 \mathrm{~ms}$, respectively, within each $2 \mathrm{sec}$. Data were analyzed in a two-way mixed between-within ANOVA including 2 (groups: TD vs. LMC) x 4 (visual condition: FV, LV-150, LV-100 \& NV) with repeated-measures on the last factor $(p \leq .05)$. Results indicated that TD children walked faster and with longer strides than LMC children in which these parameters can influence on different periods of gait cycle including stance and swing phases. Also, perceiving visual information for $150 \mathrm{~ms}$ in comparison to $100 \mathrm{~ms}$ while walking was enough for similar performance in FV condition. The present findings highlight underlying parameters of gait cycle for walking in TD compared to LMC children are different.
\end{abstract}

Key words: visual information; motor performance; walking pattern; optojump.

\section{Resumen}

La importancia de la visión y del control visual en el movimiento es un asunto ampliamente abordado y tratado en la literatura científica referida al control motor. Muchos estudios han demostrado que los niños con un bajo nivel de competencia motriz dependen en mayor medida de la visión para realizar diferentes movimientos respecto de sus iguales. El objetivo de este estudio fue destacar el efecto que diferentes condiciones visuales tenían en el rendimiento motor durante la marcha en niños con diferente nivel de coordinación motriz. Los participantes $(n=8, M a=8.5$ años sd. \pm 0.5$)$ fueron divididos en dos grupos: desarrollo motor típico (TD) y coordinación motora baja (LMC). Los participantes debían andar dentro de un laboratorio portátil $(15 \times 3 \times 2.5 \mathrm{~m})$, a lo largo de un pasillo de 10 metros donde se instaló el instrumento Optojump-Next. Dicha construcción, rodeada de una tela óscura, permitía que todos los participantes tuvieran la misma información visual durante el experimento. Los participantes anduvieron a la velocidad que deseaban bajo cuatro condiciones visuales distintas: visión completa (FV), visión reducida $150 \mathrm{~ms}$ (LV-150), visión reducida $100 \mathrm{~ms}$ (LV-100) y no visión (NV). Para la visión reducida (LV-150 y LV-100), los participantes vestían unas gafas de oclusion que se cerraban a los 100 y $150 \mathrm{~ms}$ respectivamente, cada dos segundos. Los resultados fueron analizados siguiendo un análisis doble de la varianza (ANOVA) que incluía 2 (grupos: TD vs. LMC) x 4 (condiciones visuals: FV, LV-150, LV-100 \& NV) con medidas repetidas en el último factor ( $p \leq .05)$. Los resultados de este estudio indicaron que los niños del grupo TD andaban más rápido y con zancadas más largas que los niños del grupo LMC en cuyo grupo, estos parámetros pueden influir en diferentes fases del ciclo de la marcha. Asimismo, percibir información visual durante la marcha en 150 ms. en comparación con 100 ms. fue suficiente para un rendimiento similar bajo la condición de FV. Los descubrimientos de este estudio ponen de manifiesto que bajo los parámetros de la marcha son diferentes al comparar niños con TD niños LMC.

Plabras clave: información visual; rendimiento motor; patrón de la marcha; optojump.

Correspondence/correspondencia: Miriam Palomo-Nieto

Faculty of Physical Culture. Palacky University. Olomouc (Czech Republic)

Email: miriam.palomo.nieto@gmail.com 
Palomo-Nieto, M.; Psotta, R.; Adrian, A.; Abdollahipour, R., \& Valtr, L. (2015). The effects of various visual conditions on the gait cycle in children with different level of motor coordination-a pilot study. RICYDE. Revista internacional de ciencias del deporte, 42(11), 387-399.

http://dx.doi.org/10.5232/ricyde2015.04207

\section{Introduction}

Children with deficits in motor skills are claimed to have Developmental Coordination Disorder, DCD (American Psychiatric Association, 2013). A feature of this specific disorder in motor development is the fact that these delays can not be explained as a result of intellectual delay, a diagnosed medical disease or adverse environmental conditions in which the child develops (Hernderson \& Barnett, 1998). These children with DCD show motor problems in every motor domain such as fine motor skills like buttoning, using scissors or handwriting (Barnett \& Henderson, 2005; Smits-Engelsman, Duysens \& vanGalen, 2001, Smits-Engelsman, Wilson, Westenberg \& Duysens, 2003), gross motor impairment such as running, jumping or climbing (Gallahue \& Ozmun, 1998, Haywood \& Getchell, 2001) or balance problems (Henderson \& Hall, 1982; Forseth \& Sigmundsson, 2003; Pless, Persson, Sundelin, \& Carlsson, 2001).

Many researchers have focused their studies on understanding the mechanism that underlie those motor problems. In fact DCD in the children is a heterogeneous syndrome and movement difficulties have been observed under different sensorimotor impairments (Templin, Rietdyk, Claxton \& Savage, 2014). Usually, it is assumed that DCD can be underlied by problems with the different processes involved in the information processing such as visual and/or kinaesthetic perception, assuming that the lacks in visual perception are common among children with DCD (for a review see Wilson \& McKezie, 1998). In addition, the lower ability of the perception integration, both identification or differentiation of the sensory stimuli; and/or planning, selection movement response, organizing and sequencing motor response can cause the general impairment in motor coordination (Ayres, 1972; Williams, 2002). Moreover, DCD can be associated with problems in executing of movements although a child is able to process information and plan of motor response (Zounkova \& Kolar, 2013; Mandich, Poltajko, Missiuna \& Miller, 2001).

Walking is one of the main skills of locomotion that occurs in daily life and whose domain is critical for other more complex locomotion skills such as running, jumping, hopping, skipping or stair climbing (Larkin \& Hoare, 1991). Complex and dynamical internal forces allow to humans to maintain the gait and walking. However, the current research has not shown a critical cause about how these internal forces "play" to allow us to be bipedal. Several biomechanical models (Arnold, Ward, Lieber, \& Delp, 2010; Li, Haddad, \& Hamill, (2005) have tried to understand how can we able to coordinate these forces to control our movements. Despite the importance of the walking, so far, only few research have focused on the analysis of the gait pattern, limited to some qualitative analysis (Larkin \& Hoare, 1991) and other quantitative studies (Deconinck et al., 2006b; Williams et al., 2010; Cherng et al., 2009) in children with DCD. For the postural control, that is important to walk, three sensory systems allow to maintain the upright position: vestibular, propioceptive and vision, so that perceptual information is important for walking. However, perceptual problems are often reported as common in the DCD children.

In any case, the importance of vision and the visual control of the movement have been labeled as one of the most important factors of the motor control (Schmidt \& Lee, 2011). Also the visual inputs provide vital information for helping people to modify the walking pattern (Finley, Statton \& Bastian, 2014). Some studies have demonstrated that children with DCD may rely more 
Palomo-Nieto, M.; Psotta, R.; Adrian, A.; Abdollahipour, R., \& Valtr, L. (2015). The effects of various visual conditions on the gait cycle in children with different level of motor coordination-a pilot study. RICYDE. Revista internacional de ciencias del deporte, 42(11), 387-399.

http://dx.doi.org/10.5232/ricyde2015.04207

heavily on vision to perform movement skills than their TD peers (Deconinck, DeClerq, Saverlsbergh, VanCoster, Oostra \& Dewitte, 2006a; Missiuna, Rivard, \& Barlett, 2003). However, it has been shown that children with DCD have had a greater deficiency in visual spatial processing in both with or without motor component tasks, suggesting that children with DCD could have lacks in the visual information processing, especially visual-spatial aspects (Wilson \& McKenzie, 1998). Since the visual information in both motor planning and motor control is crucial in the majority of human movements, it could be assumed that the movements will be impaired in the case of visual reduction (Schoemaker, Van der Wees, Flapper, VerhejiJansen, Scholten-Jaegers \& Geuze, 2001). Thus, the lack of visual information can affect accuracy, speed and other aspects of movement execution (Jeannerod, 1988). To investigate those possible impairments related to the motor control in children with a lower level of motor coordination, the aim of the study was to examine differences in gait pattern during walking under four different visual conditions.

\section{Methods}

\section{Participants}

Eight children (mean age $=8.5$ years old \pm 0.5 ) participated in the study. They were divided into two groups including four Typical Development (TD) children and four Low Motor Coordination (LMC) children. To be included in one of the groups the children were assessed by the Movement Assessment Battery for Children-2 (MABC-2) (Henderson, Sudgen \& Barnett, 2014). Based on the total test score (TTS) and following the rules for interpretation of MABC-2 scores, the children were divided into the two motor competence groups: TD group (children with TTS $>15^{\text {th }}$ percentile) and LMC group (children with TTS $<16^{\text {th }}$ percentile). Only children with completely physical, psychological and mental health participated in this study. Hence, those children whose movement impairments were due to a medical condition were excluded from the study. Children from TD and LMC groups did not differ significantly from each other in body weight, height and functional leg length (Table 1). The ethical approval of the present research was obtained from the review board of the university. A written informed consent was also obtained from all parents of the children and the school principles. Children were not aware of the purpose of the study.

Table 1. Results of the anthropometric measurements.

\begin{tabular}{llll}
\hline & Weight $(\mathrm{kg})$ & Height $(\mathrm{cm})$ & Leg length $(\mathrm{cm})$ \\
\hline TD & $29.1 \pm 6.7$ & $133.6 \pm 5.4$ & $74.5 \pm 6.2$ \\
LMC & $29.0 \pm 9.6$ & $127.8 \pm 5.1$ & $66.7 \pm 2.2$ \\
P value & $\mathrm{p}=0.401$ & $\mathrm{p}=0.687$ & $\mathrm{p}=0.790$ \\
\hline
\end{tabular}

\section{Equipment and Material}

Anthropometric Assessment

To calculate the weight, Tanita BF-350350 (Tanita Corp Japan) analyzer with accuracy $0.1 \mathrm{~kg}$ was used. For the assessment of the body height a portable anthropometer Leicester High 
Measure MKII (Leicester, Great Britain) with accuracy of $0.1 \mathrm{~cm}$ was used. The functional leg length (meter) (Gross et al., 2005) was measured from the spina iliaca anterior superior to the malleolus medialis. To calculate the scaled variables of gait pattern (see below), the step length (heel to heel), and the walking speed were scaled by using the leg length according to the following method proposed by Hof (1996):

$$
\begin{aligned}
& \text { Scaled step length }=\frac{\text { step length }}{\text { leg length }} \\
& \text { Scaled speed }=\frac{\text { speed }}{\sqrt{\mathrm{g} \cdot \text { leg length }}}
\end{aligned}
$$

\section{Motor Assessment}

To assess the motor coordination, the MABC-2 test (Henderson, Sugden \& Barnett, 2007) was performed for all participants. This test is made up by eight tasks divided into three categories: a) manual dexterity; b) aiming and catching and c) static and dynamic balance.

\section{Gait Assessment}

The Optojump Next instrument (Optojump Next, Version 1.3.20.0, Microgate, Bolzano, Italy) was used to measure the distance, time and speed variables while walking. This equipment consists of two different kind of bars (10 transmitting and 10 receiving bars), one meter length each, located parallel on the floor separated from each other three meters $(10 \times 3 \mathrm{~m})$.

\section{Task Equipment}

A portable laboratory $(15 \times 3 \times 2.5 \mathrm{~m})$, specifically created for the study, was used in every experiment. The Optojump equipment was placed on the ground inside the portable lab. This portable lab was built with a metallic structure completely covered by a dark blue fabric surrounding the structure from 4 sides. The roof of the structure was not covered. The purpose of using portable lab equipment was to ensure that every child has received the same visual information. The portable lab could eliminates disturbing attention of the participants and to control those children could not be disrupted through different stimuli in the environment.

The PLATO Visual Occlusion Spectacles (Portable Liquid-Crystal Apparatus for Tachistoscopic Occlusion, Translucent Technologies Inc.) were used to manipulate visual information under limited visual conditions for the participants.

\section{Procedure}

Each child was required to enter into walkway separately. Each participant was asked to walk inside the walkway in a comfortable speed under normal visual condition one time to become familiar with the task. Then, s/he was requested to walk two times through the walkway under each of four different visual conditions: full vision (FV), limited vision 150 (LV150), limited vision 100 (LV100) and non-vision (NV) condition (see below walking tasks). Participants in each group performed the task in a counter-balanced order of visual condition. Each child started behind a start line that was placed two meters before the walkway and they were asked to walk 
Palomo-Nieto, M.; Psotta, R.; Adrian, A.; Abdollahipour, R., \& Valtr, L. (2015). The effects of various visual conditions on the gait cycle in children with different level of motor coordination-a pilot study. RICYDE. Revista internacional de ciencias del deporte, 42(11), 387-399.

http://dx.doi.org/10.5232/ricyde2015.04207

until the end line that was placed two meters after the walkway to minimize the effect of acceleration and deceleration and to record only the stable gait pattern. Each participant was able to understand the task to perform it. However, if s/he made a mistake due to the impulsiveness or misunderstanding $\mathrm{s} /$ he was required to repeat that trial after explaining the correct format of the task. None of the participants failed more than once. Children wore the same light sport shoes in white line with elastic instep and plastic sole in their required sizes.

\section{Walking Test}

Participants were asked to walk at their self-selected and comfortable speed along the 10 meters walkway and start when the researcher gave them permission to walk. In the FV condition they walked in a normal vision condition without PLATO Visual Occlusion Spectacles. In each of LV150 and LV100 condition participants wore the PLATO Visual Occlusion Spectacles that shut for 2 seconds and opened for 150 in LV-150 and $100 \mathrm{~ms}$ in LV-100 condition while walking. In the NV condition participants walked in a blinded condition using a fabric eye mask to covere the eyes.

\section{Data Analysis}

The data were recorded from the first fourteen steps, i.e. seven gait cycles. The walking pattern was assessed with the selected variables obtained by Optojump including a) distance variables: scaled step length and stride length $(\mathrm{m})$; b) speed variable: scaled speed $\left(\mathrm{m} . \mathrm{s}^{-1}\right)$; c) time variables in second (s) and percentage (\%): stance phase and swing phase. Particularly, stance phase begins with the contact of the heel and finishes with the set off of the tip of the same foot. Swing phase starts when the tip of the foot leaves the ground and finishes with the contact of the heel.

All the gait cycle variables were analyzed in a two way mixed-effect (between-within) ANOVA including 2 (groups: TD vs. LMC) x 4 (vision: FV, LV150, LV100 \& NV) with repeated measurement on the last factor $(\alpha<.05)$. The Bonferroni adjustments and paired wise comparison post-hoc tests were used. Greenhouse-Geisser epsilon values were used to adjust the degree of freedom in the ANOVAs with repeated measurements to compensate for deviations from the assumption of sphericity, if necessary. T-test analyses were done for the anthropometric data and TTS. All the analyses were performed using the statistical software SPSS-21 (IBM, USA).

\section{Results}

\section{The variables of the gait pattern in the different groups and visual conditions}

\section{Distance variables}

Step length

Mauchly's test indicated that the assumption of sphericity had been violated for step length $(\chi 2(5)=13.40, p<.05)$, therefore degrees of freedom were corrected using Greenhouse-Geisser estimates of sphericity for step length $(\varepsilon=.05)$. The motor coordination level of the groups of children had a significant effect on the step length, showing that TD children $(M=.84 \pm .28)$ walked with longer strides compared to the children from the LMC group $(M=.48 \pm .15)$, 
Palomo-Nieto, M.; Psotta, R.; Adrian, A.; Abdollahipour, R., \& Valtr, L. (2015). The effects of various visual conditions on the gait cycle in children with different level of motor coordination-a pilot study. RICYDE. Revista internacional de ciencias del deporte, 42(11), 387-399.

http://dx.doi.org/10.5232/ricyde2015.04207

regardless the visual condition. Furthermore, the interaction of group $\mathrm{x}$ vision was not significant, $p>.05$. (Table 2)

Also, the main effect of vision for step length was significant (Table 2). Post-hoc test results showed that children in FV $(M=.73 \pm .30)$ walked significantly with longer step length than NV $(M=.61 \pm .35)$. Also, step length in LV150 $(M=.70 \pm .28)$ was significantly longer than LV100 $(M=.60 \pm .23)$.

\section{Stride length}

Mauchly's test indicated that the assumption of sphericity had not been violated for stride length $(\chi 2(5)=7.12, p<.05$, therefore Sphericity-assumed correction was used $(\varepsilon=.22)$. The motor coordination level of the groups of children had a significant effect on the stride length, showing that TD children $(M=114.45 \pm 14.85)$ walked with longer strides compared to the children from the LMC group $(M=93.05 \pm 11.31)$, regardless the visual condition. Furthermore, the interaction of group $\mathrm{x}$ vision was not significant, $p>.05$. (Table 2 )

Besides, the main effect of vision for stride length was significant (table 2). Post-hoc test results revealed that children in FV $(M=111.78 \pm 17.40)$ walked significantly with longer stride length than NV $(M=95.03 \pm 14.30)$ and LV100 $(M=98.62 \pm 17.80)$. Also, stride length in LV150 $(M=109.58 \pm 15.41)$ was significantly longer than LV100 and NV.

Table 2. Means, standard deviations and statistical outcome of the repeated measures ANOVA for the length variables.

\begin{tabular}{lllllll}
\hline Variable & Condition & TD children & LMC children & Group & Vision & Group x Vision \\
\hline $\begin{array}{l}\text { Scaled } \\
\text { Step }\end{array}$ & FV & $0.922 \pm 0.327$ & $0.556 \pm 0.136$ & $F(1,6)=4.71$ & $F(1.25,7.54)=6.9$ & $F(1.25,7.54)<1$ \\
Length & LV150 & $0.886 \pm 0.265$ & $0.523 \pm 0.163$ & $p=.073$ & 0 & $p=.564$ \\
& LV100 & $0.754 \pm 0.204$ & $0.446 \pm 0.164$ & & $\begin{array}{l}\eta=.028 \\
p^{2}=.535\end{array}$ & \\
& NV & $0.820 \pm 0.405$ & $0.405 \pm 0.150$ & & & \\
Stride & FV & $124.37 \pm$ & $99.18 \pm 10.88$ & $F(1,6)=6.65$ & $F(3,18)=38.34$ & $F(3,18)<2$ \\
$\begin{array}{l}\text { Length } \\
\text { (cm) }\end{array}$ & & 12.86 & & $p=.042$ \\
& LV150 & $121.26 \pm$ & $97.90 \pm$ & $\eta p^{2}=.526$ & $\eta p^{2}=.865$ & $p=.212$ \\
& & 9.34 & 10.18 & & & \\
& LV100 & $107.91 \pm$ & $89.33 \pm$ & & & \\
& & 18.75 & 10.36 & & & \\
& NV & $104.27 \pm$ & $85.79 \pm$ & & & \\
& & 10.49 & 11.83 & & & \\
& & & & & & \\
\end{tabular}

\section{Speed variable}

Mauchly's test indicated that the assumption of sphericity had not been violated for speed variable $(\chi 2(5)=4.13, p>.05)$, therefore Sphericity-assumed correction was used $(\varepsilon=.41)$. 
Palomo-Nieto, M.; Psotta, R.; Adrian, A.; Abdollahipour, R., \& Valtr, L. (2015). The effects of various visual conditions on the gait cycle in children with different level of motor coordination-a pilot study. RICYDE. Revista internacional de ciencias del deporte, 42(11), 387-399.

http://dx.doi.org/10.5232/ricyde2015.04207

Regarding the speed, the results showed that TD children $(M=1.53 \pm .21)$ walked significantly faster than LMC children $(M=1.26 \pm .23)$ regardless the vision condition. Furthermore, the speed of walking decreases while the occlusion time increases regardless the level of motor competence. Besides, the interaction between group $\mathrm{x}$ vision was not significant, $p>.05$. (Table 3 )

Besides, the main effect of vision for speed of walking was significant (table 3). Post-hoc test results showed that children in FV $(M=1.56 \pm .23)$ walked significantly faster than LV100 $(M=1.28 \pm .21)$.

Table 3. Means, standard deviations and statistical outcome of the repeated measures ANOVA for the speed variable.

\begin{tabular}{lllllll}
\hline Variable & Condition & TD children & LMC children & Group & Vision & Group x Vision \\
\hline $\begin{array}{l}\text { Scaled } \\
\begin{array}{l}\text { Speed } \\
\left(\mathrm{ms}^{-1}\right)\end{array}\end{array}$ & FV & $1.733 \pm 0.042$ & $1.405 \pm 0.237$ & $F(1,6)=6.18$ & $F(3,18)=4.35$ & $F(3,18<1$ \\
& LV150 & $1.479 \pm 0.301$ & $1.308 \pm 0.198$ & $\begin{array}{l}p=.047 \\
p^{2}=.440\end{array}$ & $\begin{array}{l}\eta p^{2}=.535 \\
\end{array}$ \\
& LV100 & $1.433 \pm 0.100$ & $1.128 \pm 0.196$ & & & \\
& NV & $1.502 \pm 0.215$ & $1.205 \pm 0.279$ & & & \\
& & & & & \\
\hline
\end{tabular}

\section{Time variables}

The time variables were divided into the absolutes scores (that is the total time spent on the phase) and the percentage (percentage of the phase from the whole gait cycle). Mauchly's test indicated that the assumption of sphericity had not been violated for stance phase (time) $(\chi 2(5)=$ $9.89, p>.05)$, neither for stance phase (percentage) $(\chi 2(5)=10.22, p>.05)$, therefore Sphericityassumed correction was used for step length $(\varepsilon=.12)$ and stride length $(\varepsilon=.11)$. Overall, for time variables, the TD group showed higher values (in $\mathrm{ms}$ and \%) than the LMC ones (Table 4). Specifically, for absolute scores, the results showed that the swing phase (s) was significantly superior in TD $(M=.60 \pm .08)$ compared to LMC $(M=.32 \pm .04)$ children regardless of the visual condition. Also, stance phase (s) was significantly higher in TD $(M=.73 \pm .13)$ than LMC $(M=.37 \pm .13)$ children independent of the visual condition. However, there were not significant differences based on the visual condition irrespective of the motor competence level. Neither, the interactions of group $\mathrm{x}$ vision were significant in the absolute scores in swing phase (s) and stance phase (s) (Table 4).

Mauchly's test indicated that the assumption of sphericity had not been violated for swing phase (time) $(\chi 2(5)=6.78, p>.05)$, therefore Sphericity-assumed correction was used $(\varepsilon=.23)$. However, the assumption of sphericity had been violated for swing phase (percentage) $(\chi 2(5)=12.16$, $p=.03$ ), therefore degrees of freedom were corrected using Greenhouse-Geisser estimates of sphericity $(\varepsilon=.07)$. Regarding the percentage, the results demonstrated that all the time variables including the swing phase (\%) was significantly different between TD $(M=60.41 \pm 9.56)$ and LMC $(M=34.14 \pm 2.46)$ children regardless the visual condition. Also, stance phase (\%) was significantly different between TD $(M=66.36 \pm 3.21)$ and LMC $(M=39.13 \pm 14.97)$ children. As in 
Palomo-Nieto, M.; Psotta, R.; Adrian, A.; Abdollahipour, R., \& Valtr, L. (2015). The effects of various visual conditions on the gait cycle in children with different level of motor coordination-a pilot study. RICYDE. Revista internacional de ciencias del deporte, 42(11), 387-399.

http://dx.doi.org/10.5232/ricyde2015.04207

the absolutes scores, the results were not significantly different in the visual conditions regardless the motor competence level. Also, the interactions of group $\mathrm{x}$ vision were not significant in both time variables in percentage (swing phase (\%) and stance phase (\%) (Table 4).

Table 4 Means, standard deviations and statistical outcome of the repeated measures ANOVA for the time variables in time and percentage.

\begin{tabular}{|c|c|c|c|c|c|c|}
\hline Variable & Condition & TD children & LMC children & Group & Vision & Group $\mathrm{x}$ Vision \\
\hline \multirow{5}{*}{$\begin{array}{l}\text { Stance } \\
\text { Phase (s) }\end{array}$} & FV & $0.726 \pm 0.116$ & $0.725 \pm 0.113$ & \multirow{5}{*}{$\begin{array}{l}F(1,6)=17.52 \\
p=.006 \\
\eta p^{2}=.745\end{array}$} & $F(3,18)<2$ & $F(3,18<1$ \\
\hline & LV150 & $0.753 \pm 0.142$ & $0.740 \pm 0.194$ & & $p=.213$ & $p=.733$ \\
\hline & & & & & & \\
\hline & LV100 & $0.745 \pm 0.182$ & $0.729 \pm 0.154$ & & & \\
\hline & NV & $0.679 \pm 0.138$ & $0.654 \pm 0.091$ & & & \\
\hline \multirow{5}{*}{$\begin{array}{l}\text { Stance } \\
\text { Phase (\%) }\end{array}$} & FV & $67.64 \pm 3.28$ & $67.44 \pm 16.44$ & \multirow{5}{*}{$\begin{array}{l}F(1,6)=10.96 \\
p=.016 \\
\eta p^{2}=.646\end{array}$} & $F(3,18)<2$ & $F(3,18<1$ \\
\hline & LV150 & $67.99 \pm 3.69$ & $65.40 \pm 16.25$ & & $p=.299$ & $p=.526$ \\
\hline & & & & & & \\
\hline & LV100 & $65.21 \pm 3.67$ & $64.94 \pm 16.04$ & & & \\
\hline & NV & $64.62 \pm 1.44$ & $63.68 \pm 17.82$ & & & \\
\hline \multirow{4}{*}{$\begin{array}{l}\text { Swing } \\
\text { Phase (s) }\end{array}$} & $\mathrm{FV}$ & $0.348 \pm 0.041$ & $0.350 \pm 0.062$ & \multirow{4}{*}{$\begin{array}{l}F(1,6) \\
51.50 \\
p<.001 \\
\eta p^{2}=.896\end{array}$} & $F(3,18)<1$ & $F(3,18)=<2$ \\
\hline & LV150 & $0.354 \pm 0.061$ & $0.391 \pm 0.147$ & & $p=.483$ & $p=.154$ \\
\hline & LV100 & $0.397 \pm 0.059$ & $0.393 \pm 0.036$ & & & \\
\hline & NV & $0.372 \pm 0.026$ & $0.373 \pm 0.049$ & & & \\
\hline \multirow{5}{*}{$\begin{array}{l}\text { Swing } \\
\text { Phase (\%) }\end{array}$} & FV & $32.36 \pm 11.54$ & $32.56 \pm 3.06$ & \multirow{5}{*}{$\begin{array}{l}F(1,6)=31.38 \\
p=.001 \\
\eta p^{2}=.840\end{array}$} & $F(1.26,7.58)<2$ & $F(1.26,7.58)=3.87$ \\
\hline & LV150 & $32.31 \pm 6.25$ & $34.60 \pm 1.85$ & & $p=.247$ & $p=.081$ \\
\hline & LV100 & & $3506+199$ & & & \\
\hline & 年 & 格 & $0000+1.03$ & & & \\
\hline & NV & $35.38 \pm 14.15$ & $36.32 \pm 1.46$ & & & \\
\hline
\end{tabular}

\section{Discussion}

The main goals of the study were to compare the spatio-temporal parameters of the gait cycle of walking under full vision, limited vision 150, limited vision 100 and non-vision conditions between LMC and TD children. The results of the quantitative assessments achieved by the Optojump instrument demonstrated that the walking performance of the TD children was significantly different from the children with LMC. These differences while walking were found in all time variables including stance phase $(\%$ and $s)$ and swing phase $(\%$ and $s)$. In addition, 
Palomo-Nieto, M.; Psotta, R.; Adrian, A.; Abdollahipour, R., \& Valtr, L. (2015). The effects of various visual conditions on the gait cycle in children with different level of motor coordination-a pilot study. RICYDE. Revista internacional de ciencias del deporte, 42(11), 387-399.

http://dx.doi.org/10.5232/ricyde2015.04207

only stride length $(\mathrm{m})$ in distance variables was significantly longer in the TD children comparing to their LMC peers. Moreover, the scaled step speed $\left(\mathrm{m} . \mathrm{s}^{-1}\right)$ was faster in the TD than in the LMC children. Overall, this results suggest that dysfunctions in walking of children observed between TD and DCD children in qualitative research (Larkin \& Hoare 1991; Woodruff, 2002) could be found in majority of parameters of gait cycle. In the same line (Deconinck et al., 2006b) reported that TD children walked faster than their DCD peers on a treadmill. Nevertheless, those results should be carefully compared while walking on a treadmill could require different strategies to move on a moving and instable surface. Also, the results of the current research are somehow in accordance with those from Cherng et al. (2009) and Williams et al. (2010) in which children with and without DCD showed little or no difference between them in gait parameters under a normal vision walking. However, the study reported greater differences under dual or more challenging walking conditions.

Also, the current research shows that there were significant differences between groups in time and percentage in the stance phase (s) in which the time that TD spent on stance phase was longer than in the LMC children, supporting the idea that LMC children have balance problems (Cherng et al., 2007; Geuze 2003; Tsai et al., 2008) and similarly they spend more time in those parameters that were related to double support (Cermak and Larkin 2002; Deconinck et al., 2006b; Sudgen and Chambers 2005).

The results of this study showed also that the performance of the children was different between the vision conditions irrespective of the different level of motor competence in the length variables including scaled step length and stride length $(\mathrm{cm})$ and in the speed variable, including scaled step speed $\left(\mathrm{ms}^{-1}\right)$. These results suggest that limitation in receiving visual information under NV and LV100 could affect the time and speed variables of gait cycle showing that children walked slower with shorter step lengths under receiving NV or restricted visual information. Also, the present results highlight the importance of visual information for walking. Walking as a locomotion task is a goal-directed motor skill and visual input can influence navigation of walking (Patla, 1997). Specifically, in the scaled step length, stride length and scaled step speed there were significant differences between FV and LV100 and NV condition, and also between LV150 and LV100 and NV regardless of motor competence groups. These results shows that gait pattern in the FV and LV150 conditions was similar, suggesting that $150 \mathrm{~ms}$ is enough time to perceive visual information similar to $\mathrm{FV}$ to perform normal gait pattern. Yet, it seems that $100 \mathrm{~ms}$ is not enough time to perceive visual inputs to walk normally in children irrespective of the level of motor competence. These results demonstrated that visual information had an important influence on the spatial parameters (speed and distance variables) of the gait cycle in the children (Deconinck et al., 2006a; Williams et al., 2010). However, the time parameters such as swing phase (s and \%) and stance phase (s and \%) did not differ between visual conditions, supporting the possibility that other information inputs as proprioceptive one could contribute more efficiently for these parameters (Tremblay, 2010). This interpretation can be supported by findings in which the minimum time of exposition of stimulus to be detected is between 100 and 150ms (Schmidt and Lee 2011; Vickers 2007). However the inconsistency in some of the post hoc analysis also suggest that more participants are needed to confirm this approach. 
Another limitation of this study is also that this model has been primarily focused on motions supported entirely by the lower extremity and it has not been considered the upper extremity as a part of the support and control of locomotion (Russell et al., 2012). Also, lack of interactions between groups and visual conditions might limit interpretation of results for this research due to difficulty in finding children with DCD. However, the present findings highlight some signs for deeper analysis of walking pattern in children with and without DCD.

In conclusion, the current study demonstrated performance of TD and LMC children are different from each other in some parameters (stride length and speed) of gait cycle in which they can influence on both phases of gait cycle (stance phase and swing phase). Also, critical time for perceiving visual information while walking in children could be between $150 \mathrm{~ms}$ and $100 \mathrm{~ms}$. Future studies should consider a larger number of participants to give us a clearer interpretation about process of visual information in children with different levels of motor competence.

\section{Acknowledgements}

The study was supported by the project: Support for Creating Excellent Research Teams and Intersectoral Mobility at Palacký University in Olomouc II. Reg. no: CZ.1.07/2.3.00/30.0041, financially supported by the EU Structural Funds.

\section{References}

American Psychiatric Association. (2013). Diagnostic and statistical manual of mental disorders 5th ed. (DSM-5TM). Washington, DC: American Psychiatric Press.

Arnold, E.; Ward, S.; Lieber, R., \& Delp, S. (2010). A model of the lower limb for analysis of human movement. Annals of Biomedical Engineering, 38, 269-279. http://dx.doi.org/10.1007/s10439-009-9852-5

Ayres, J.A. (1972). Sensory integration and learning disorders. Los Angeles, CA: Western Psychological Services.

Barnett, A., \& Henderson, S.E. (2005). Assessment of handwriting in children with developmental coordination disorder. In D. A. Sugden \& M. E. Chambers (Eds.), Children with Developmental Coordination Disorder (pp. 168-188). London: Whurr Publishers.

Cermak, S. A., \& Larkin, D. (2002). Developmental coordination disorder. Albany, NY: Thomson Learning.

Cherng, R.J.; Hsu, Y.W.; Chen, Y.J., \& Chen, J.Y. (2007). Standing balance of children with developmental coordination disorder under altered sensory conditions. Human Movement Science, 26(6), 913-926. http://dx.doi.org/10.1016/j.humov.2007.05.006

Cherng, R.J.; Liang, L.Y.; Chen, Y.J., \& Chen, J.Y. (2009). The effects of a motor and cognitive task on walking in children with developmental coordination disorder. Gait \& Posture, 29(2), 204-207.

http://dx.doi.org/10.1016/j.gaitpost.2008.08.003 
Deconinck, F.J.A.; DeClerq, D.; Savelsbergh, G.H.P.; VanCoster, R.; Oostra, A.; Dewitte, G., \& Lenoir, M. (2006a). Visual contribution to walking in children with developmental coordination disorder. Child: Care, Health \& Development, 32(6), 711-722. http://dx.doi.org/10.1111/j.1365-2214.2006.00685.x

Deconinck, F.J.A.; DeClerq, D.; Savelsbergh, G.H.P.; VanCoster, R.; Oostra, A.; Dewitte, G., \& Lenoir, M. (2006b). Differences in gait between children with and without developmental coordination disorder. Motor Control, 10(2), 125-142.

Finley, J.M.; Statton, M.A., \& Bastian, A.J. (2014). A novel optic flow pattern speeds splitbelt locomotor adaptation. Journal of Neurophysiology, 111(5), 969-976. http://dx.doi.org/10.1152/jn.00513.2013

Forseth, A.K., \& Sigmundsson, H. (2003). Static balance in children with hand-eye coordination problems. Child: Care, Health \& Development, 29(6), 569-579. http://dx.doi.org/10.1046/j.1365-2214.2003.00378.x

Gallahue, D.L., \& Ozmun, J.C. (1998). Understanding motor development: Infants, children, adolescents, adults (4th ed.). Boston, MA: WCB/McGraw-Hill.

Geuze, R.H. (2003). Static balance and developmental coordination disorder. Human Movement Science, 22(4-5), 527-548.

http://dx.doi.org/10.1016/j.humov.2003.09.008

Gross, J.; Fetto, J., \& Rosen, E. (2005). Vyšetření pohybového aparátu. Musculo eskeletal examination. Praha: Triton.

Haywood, K.M., \& Getchell, N. (2001). Lifespan motor development (3rd ed.) Champaign, IL: Human Kinetics.

Henderson, S.E., \& Barnett, A.L. (1998). Developmental movement problems. In J. Rispens, T. Van Yperen, \& W. Yule (Eds.), Perspectives on the classification of specific developmental disorders. Dordrecht: Kluwer. http://dx.doi.org/10.1007/978-94-017-2581-1_10

Henderson, S.E. \& Hall, D. (1982). Concomitants of clumsiness in young shoolchildren. Developmental Medicine and Child Neurology, 24, 448-460.

http://dx.doi.org/10.1111/j.1469-8749.1982.tb13649.x

Henderson, S.E.; Sugden, D.A., \& Barnett, A.L. (2007). Movement Assessment Battery for Children-2. London: Harcourt Assessment.

Henderson, S.E.; Sugden, D.A., \& Barnett, A.L. (2014). Test motoriky pro děti MABC-2. Motor test for children MABC-2. (Czech adapted version by Psotta, R.). Prague: Hogrefe-Testcentrum.

Hof, A.L. (1996). Scaling gait data to body size. Gait \& Posture, 4(3), 222-223. http://dx.doi.org/10.1016/0966-6362(95)01057-2

Jeannerod, M. (1988). The neural and behavioural organization of goal-directed movements. Oxford: Oxford University Press.

Larkin, D., \& Hoare, D. (1991). Out of step. Coordinating kids' movement. Nedlands, Western Australia Active Life Foundation.

Li, L., Haddad, J. M., \& Hamill, J. (2005). Stability and variability may respond differently to changes in walking speed. Human Movement Science, 24, 257-267.

http://dx.doi.org/10.1016/j.humov.2005.03.003 
Mandich, A.; Polatajko, H.J.; Missiuna, C., \& Miller, L.T. (2001). Cognitive strategies and motor performance in children with developmental coordination disorder. Journal of Physical \& Occupational Therapy in Pediatrics, 20(2-3), 51-68.

http://dx.doi.org/10.1080/J006v20n02_04

Missiuna, C.; Rivard, L., \& Bartlett, D. (2003). Early identification and risk management of children with developmental coordination disorder. Journal of Pediatric Physical Therapy, 15(1), 32-38.

http://dx.doi.org/10.1097/01.PEP.0000051695.47004.BF

Patla, A. (1997). Understanding the roles of vision in the control of human locomotion. Gait and Posture, 5, 54-69. http://dx.doi.org/10.1016/S0966-6362(96)01109-5

Pless, M.; Persson, K.; Sundelin, C., \& Carlsson, M. (2001). Children with developmental coordination disorder: A qualitative study of parents' descriptions. Advances in Physiotherapy, 3(3), 128-135.

http://dx.doi.org/10.1080/140381901750475375

Russell, S.D.; Zirker, C.A., \& Blemker, S.S. (2012). Computer models offer new insight into the mechanics of rock climbing. Sport Technology, 5(3-4), 120-131.

Schmidt, R.A., \& Lee, T.D. (2011). Motor control and learning. A behavioural emphasis. Champaign, IL: Human Kinetics.

Schoemaker, M.; Van der Wees, M.; Flapper, B.; Verheij-Jansen, N.; Scholten-Jaegers, S., \& Geuze, R.H. (2001). Perceptual skills of children with developmental coordination disorder. Human Movement Science, 20(1-2), 111-133.

http://dx.doi.org/10.1016/S0167-9457(01)00031-8

Smits-Engelsman, B.C.M.; Duysens, J., \& vanGalen, G.P. (2001). The advantage of cyclic over discrete aiming movements and its implications for a motor control superiority of cursive script. In R.G.J. Meulenbroek, \& B. Steenbergen (Eds.), Proceedings of the Tenth Biennial Conference of the International Graphonomics Society (pp. 74-77). Nijmegen: IGS.

Smits-Engelsman, B.C.M.; Wilson, P.H.; Westenberg, Y., \& Duysens, J. (2003). Fine motor deficiencies in children with developmental coordination disorder and learning disabilities: An underlying open-loop control deficit. Human Movement Science, 22(4-5), 495-513.

http://dx.doi.org/10.1016/j.humov.2003.09.006

Sugden, D., \& Chambers, M. (2005). Children with developmental coordination disorder. London: Whurr Publishers.

Tsai, C.L.; Wu, S.K., \& Huang, C.H. (2008). Static balance in children with developmental coordination disorder. Human Movement Science, 27(1), 142-153. http://dx.doi.org/10.1016/j.humov.2007.08.002

Tremblay, L. (2010). Visual information in the acquisition of goal-directed action In D. Elliott, \& M. Khan (Eds.), Vision and goal-directed movement neurobehavioral perspectives (pp. 281-291). Champaign, IL: Human Kinetics.

Vickers, J.N. (2007). Perception, cognition and decision training. The quiet eye in action. Champaign, IL: Human Kinetics. 
Palomo-Nieto, M.; Psotta, R.; Adrian, A.; Abdollahipour, R., \& Valtr, L. (2015). The effects of various visual conditions on the gait cycle in children with different level of motor coordination-a pilot study. RICYDE. Revista internacional de ciencias del deporte, 42(11), 387-399.

http://dx.doi.org/10.5232/ricyde2015.04207

Williams, H.G. (2002). Motor control in children with developmental coordination disorder. In S.A. Cermak, \& D. Larkin (Eds.), Developmental Coordination Disorder (pp. 117137). Albany, NY: Thomson Learning.

Williams, H.G.; Ashley, L., \& Ullmann, G. (2010). Gait characteristics of children with and without developmental coordination disorder: A case study. European Psychomotoricity Journal, 3(1), 4-14.

Wilson, P.H., \& McKenzie, B.E. (1998). Information processing deficits associated with developmental coordination disorder: A meta-analysis of research findings. Journal of Child Psychology \& Psychiatry, 39(6), 829-840. http://dx.doi.org/10.1017/S0021963098002765

Woodruff, S.J.; Bothwell-Myers, C.; Tingley, M., \& Albert, W.J. (2002). Gait pattern classification of children with developmental coordination disorder. Adapted Physical Activity Quarterly, 19(3), 378-391.

Zounková, I., \& Kolář, P. (2013). Central coordination disturbance in preschool and school age. In P. Kolář et al. (Eds.), Clinical Rehabilitation (pp. 125-128). Prague: Alena Kobesová. 